\title{
Identification of trisomy 18, trisomy 13, and Down syndrome from maternal plasma
}

This article was published in the following Dove Press journal:

The Application of Clinical Genetics

7 July 2014

Number of times this article has been viewed

\author{
Jean Gekas ${ }^{1,2}$ \\ Sylvie Langlois ${ }^{3}$ \\ Vardit Ravitsky ${ }^{4}$ \\ François Audibert ${ }^{5}$ \\ David-Gradus van den Berg 6 \\ Hazar Haidar ${ }^{4}$ \\ François Rousseau ${ }^{2,7}$ \\ 'Prenatal Diagnosis Unit, Department \\ of Medical Genetics and Pediatrics, \\ Faculty of Medicine, Laval University, \\ Québec City, Quebec, Canada; \\ 'Department of Medical Biology, \\ Centre Hospitalier Universitaire \\ de Québec, Québec City, Quebec, \\ Canada; ${ }^{3}$ Department of Medical \\ Genetics, University of British \\ Columbia, Vancouver, Canada; \\ ${ }^{4}$ Bioethics Program, Department \\ of Social and Preventive Medicine, \\ School of Public Health, University \\ of Montreal, Montreal, Canada; \\ ${ }^{5}$ Department of Obstetrics and \\ Gynecology, Sainte Justine Hospital, \\ Montreal, Canada; ${ }^{6}$ Department \\ of Social and Preventive Medicine, \\ ${ }^{7}$ Department of Molecular Biology, \\ Medical Biochemistry and Pathology, \\ Faculty of Medicine, Laval University, \\ Québec City, Quebec, Canada
}

Correpondence: Jean Gekas

Centre Hospitalier de l'Université Laval,

Centre Hospitalier de l'Université de

Québec, 2705 Boulevard Laurier,

Bureau RC-9300, Sainte-Foy,

Québec City, GIV 4G2,

Quebec, Canada

Tel + I 4185254444 ext 48 II 4

Fax + I 4186542748

Email jean.gekas@mail.chuq.qc.ca
Abstract: Current prenatal diagnosis for fetal aneuploidies (including trisomy 21 [T21]) generally relies on an initial biochemical serum-based noninvasive prenatal testing (NIPT) after which women who are deemed to be at high risk are offered an invasive confirmatory test (amniocentesis or chorionic villi sampling for a fetal karyotype), which is associated with a risk of fetal miscarriage. Recently, genomics-based NIPT (gNIPT) was proposed for the analysis of fetal genomic DNA circulating in maternal blood. The diffusion of this technology in routine prenatal care could be a major breakthrough in prenatal diagnosis, since initial research studies suggest that this novel approach could be very effective and could reduce substantially the number of invasive procedures. However, the limitations of gNIPT may be underappreciated. In this review, we examine currently published literature on gNIPT to highlight advantages and limitations. At this time, the performance of gNIPT is relatively well-documented only in high-risk pregnancies for T21 and trisomy 18. This additional screening test may be an option for women classified as high-risk of aneuploidy who wish to avoid invasive diagnostic tests, but it is crucial that providers carefully counsel patients about the test's advantages and limitations. The gNIPT is currently not recommended as a first-tier prenatal screening test for T21. Since gNIPT is not considered as a diagnostic test, a positive gNIPT result should always be confirmed by an invasive test, such as amniocentesis or chorionic villus sampling. Validation studies are needed to optimally introduce this technology into the existing routine workflow of prenatal care.

Keywords: prenatal diagnosis, Down syndrome, noninvasive prenatal testing, cell-free fetal DNA, informed consent, reproductive autonomy

\section{Current prenatal diagnosis for fetal aneuploidies}

Down syndrome ([DS], trisomy 21) is the most common cause of intellectual disability worldwide and affects approximately 1:500 pregnancies. ${ }^{1}$ Genetic prenatal diagnosis for fetal aneuploidies, such as trisomy 21 (Down syndrome), 13, and 18, has been an integral part of prenatal medicine for more than 40 years. To this day, definitive prenatal diagnosis of DS can only be achieved by the sampling of fetal material obtained through invasive testing (amniocentesis or chorionic villus sampling), which is associated with a 1 in 200 chance of fetal miscarriage. ${ }^{2,3}$ Therefore, to limit the number of invasive procedures, current screening programs for DS generally combine initial noninvasive risk screening strategies that use maternal serum with or without ultrasound markers in a mathematical model to estimate an overall personal risk score for each woman for carrying a fetus with DS. Women who are deemed to be at high risk are then offered invasive prenatal diagnosis. 
Current noninvasive risk screening identifies up to $90 \%$ of pregnancies with trisomies, with a screen-positive rate of $4 \%-5 \%$ in the general population. ${ }^{4}$ However, with the current prenatal genetic screening schemes, many women will undergo invasive prenatal diagnosis while not carrying an affected fetus. Hence, either a more specific screening method (ie, with a lower rate of false-positive results) or a reliable and convenient method for prenatal diagnosis (ie, with a much smaller [or absent] risk of fetal loss) has long been sought. ${ }^{5}$

\section{Genomics-based noninvasive prenatal testing (gNIPT)}

The presence of cell-free DNA released by the fetus into the circulation of its mother was reported in $1997 .{ }^{6}$ By analyzing this source of fetal genetic material, obtainable through a blood sample from a pregnant woman, gNIPT has been developed ${ }^{7}$ and proposed as potentially changing the approach to prenatal diagnosis for DS and other conditions. Cell-free fetal DNA (cffDNA) discovered in maternal plasma ${ }^{6}$ originates from placental cell turnover. ${ }^{8}$ It consists of short fragments of DNA of approximately $150 \mathrm{bp}$ in length rather than whole chromosomes, ${ }^{9}$ which represents about $5 \%-10 \%$ of the total cell-free DNA in the maternal plasma and most of which originates from the mother. ${ }^{9,10}$ The cffDNA can be detected as early in pregnancy as 4 weeks' gestation. ${ }^{11}$ It disappears rapidly from maternal blood due to a half-life of 16 minutes, and it is undetectable 2 hours after delivery. ${ }^{12}$ These characteristics make cffDNA an interesting source of fetal genetic material for gNIPT using a maternal blood sample and with the potential to eliminate the necessity of an invasive procedure in many cases. $^{13}$

Potential uses of ccfDNA include: fetal sex determination (useful for fetuses at risk of a sex-linked disease, about five in 10,000 live births); ${ }^{14}$ diagnosis of paternally inherited mutations for certain single gene disorders in known at risk families, ${ }^{15,16}$ fetal blood genotyping (fetal $\mathrm{RhD}$ typing in $\mathrm{RhD}$ negative women who are at increased risk of haemolytic disease of the newborn); ${ }^{17}$ and, more recently, the detection of fetal aneuploidies, such as DS. ${ }^{5}$ Numerous studies have shown the possibility of detecting DS, and other aneuploidies using cffDNA in maternal blood of high risk pregnancies. ${ }^{18-20}$ This new approach appears to be very effective according to studies published so far. It has been reported to detect between $98 \%-100 \%$ of fetuses who have DS with a very low false-positive rate..$^{20,21}$

Many techniques have been used to study cffDNA sequences in maternal circulation, ${ }^{5}$ most commonly quantitative polymerase chain reaction, mass spectrometry, ${ }^{22}$ digital polymerase chain reaction, ${ }^{23}$ and massively parallel DNA sequencing. ${ }^{24}$ Intrinsic differences between fetal and maternal cell-free DNA have been exploited to increase the relative amount of fetal DNA, ${ }^{5}$ including selecting the shortest DNA fragments ${ }^{9}$ and identifying universal fetal markers, such as the DNA methylation patterns. ${ }^{25}$

The principle of the approach for gNIPT for DS is based on the identification of the chromosomal origin (and counting) of several millions of small fragments of cffDNA using various molecular methods to quantitatively enumerate sequences (or reads) of the chromosome of interest (for example, chromosome 21) and compare to the number expected in an unaffected pregnancy. ${ }^{20,21}$ If the fetus has DS, a small relative increase in chromosome 21 DNA fragments among all cffDNA molecules in maternal plasma should be detected in comparison to unaffected pregnancies. The same applies for other significant trisomies, such as for chromosomes 13 and 18. 7,24,26

Recently, three published prospective studies, each involving more than 500 high-risk pregnancies, investigated the performance of gNIPT for $\mathrm{DS}^{27-29}$ with full karyotyping results available. They showed the possible clinical applicability of these methods. Over all, gNIPT offers a detection rate more than $99 \%$ and a false-positive rate under $0.5 \%$ in high-risk pregnancies. ${ }^{27-29}$ Also, the test's positive predictive value, which reflects the probability that a positive test result indicates a true fetal aneuploidy in high-risk groups of women for DS, is impressively high (97.94\%). ${ }^{4}$

However, the rate of non-reportable results, depending on the inclusion criteria for pregnant women and technical protocol used, ranged from $1 \%-5 \% .{ }^{27-29}$

Professional groups ${ }^{30-32}$ have published clinical recommendations regarding the use of gNIPT for fetal aneuploidy detection. Together, the National Coalition for Health Professional Education in Genetics and the National Society of Genetic Counselors in the US, the International Society for Prenatal Diagnosis, the Society of Obstetricians and Gynecologists of Canada, and the California Technology Assessment Forum, stated that gNIPT could be an option for fetal aneuploidy detection in high-risk pregnancies after nondirective counseling by qualified personnel..$^{33,34}$

\section{Limitations of gNIPT technologies}

Some limitations appear for the use of gNIPT technologies in prenatal diagnosis for fetal chromosomal abnormalities testing. Even if these studies reported excellent performances with overall detection rates for trisomy 21 
exceeding $99 \%$ with false-positive rates of less than $1 \%$, many elements need to be taken into consideration:

1. To date, while a reasonable amount of evidence supports the use of gNIPT in high-risk women for detection of fetal trisomy 21 and $18,{ }^{30-32}$ no studies have addressed the cost effectiveness of gNIPT implementation in a routine real-life pregnancy health care workflow setting. ${ }^{3,5,35}$

2. Available data addressed the diagnostic performances of gNIPT for: fetal aneuploidies among women classified to be at high risk for fetal aneuploidy for advanced maternal age; personal history of birth for trisomies 21,18 , or 13; suggestive ultrasound findings; or being screened positive by conventional aneuploidy screening protocols. The applicability of gNIPT in normalrisk pregnancies is currently evaluated by ongoing studies. ${ }^{36}$

3. Chromosome anomalies other than trisomies 21 and 18 and other cryptic genomic imbalances could result in an important rate of false-negative results with gNIPT technology. There is less evidence on the efficacy of the use of gNIPT for trisomy 13 and monosomy $\mathrm{X}$, while trisomy 13 and monosomy $\mathrm{X}$ are included in common fetal chromosomal aneuploidies that are targeted in conventional prenatal diagnosis. Notably, the important guanine and cytosine nucleotide contents of chromosomes 18 and 13, may result in insensitive detection for those chromosomes. ${ }^{7,24,26}$ Some optimized technical protocols, to correct this guanine and cytosine bias, ${ }^{37-39}$ produced a high detection rate for trisomy $18,{ }^{18,27-29,38}$ but due to the lower incidence of trisomy 13 , the number of cases available for evaluation by genomic technologies and gNIPT has been smaller. Ten to 25 recruited cases were reported in four studies, ${ }^{18,27,29,38}$ while the number of nontrisomy cases in the same studies analyzed ranged from 264-1,939. The mean detection rate for trisomy 13 in these four studies was only $87.6 \%$, which one could consider as an insufficient detection rate in a prenatal diagnosis context. Also, for monosomy X, the failure rate could be as high as $13 \%$ of samples analyzed. ${ }^{18,26,27,38}$ In addition, triploidies occur in $2 \%-3 \%$ of conceptuses and are estimated to occur in 1 in 30,000 pregnancies at 16 weeks. ${ }^{40}$ The fact that gNIPT testing may not accurately guarantee their detection ${ }^{40-42}$ highlights the importance of routine chromosome analysis on all prenatal diagnoses with multiple congenital anomalies prior to the consideration of more complex genetic testing. ${ }^{40}$ In a study evaluating the diagnostic yield of chromosomal microarray analysis as compared with karyotyping for routine prenatal diagnosis, in samples with a normal karyotype, microarray analysis revealed clinically relevant deletions or duplications in $6.0 \%$ of fetuses with a structural anomaly seen at ultrasonography and in $1.7 \%$ of those whose indications were advanced maternal age or positive screening results. Obviously, these cases would not be detected by gNIPT.43 Also, of karyotypes yielding results in the Eunice Kennedy Shriver National Institute of Child Health and Human Development prenatal cytogenetic array study, which involved 4,401 women, ${ }^{44}$ 179 cases having an abnormality other than trisomy 21 and trisomy 18 were reported, representing $4.2 \%$ of women. ${ }^{44}$ So, in the context of a structural abnormality seen on ultrasound, invasive diagnostic testing for chromosomal analysis (karyotyping and microarray) would provide a higher diagnostic yield than gNIPT.

4. False-positive and false-negative gNIPT results may occur at a higher rate than previously reported in clinical trials. ${ }^{35}$ No studies correlated test results with maternal and fetal chromosomes at delivery since cell-free fetal DNA is maternal and placenta origin and maternal somatic mosaicism and confined placental mosaicism can affect gNIPT results. ${ }^{35}$ False-positive results have been reported because of confined placental mosaicism including for trisomy $21.35,36,45$

5. Existing data for twin pregnancies are insufficient for the moment. ${ }^{46,47}$

6. Costs of gNIPT are presently significantly higher (up to two orders of magnitude) than those of prenatal screening in publicly funded health care systems. This may influence its cost-effectiveness as a first-tier test.

7. Since gNIPT does not screen for open neural tube defects, maternal serum alpha-fetoprotein testing and/or fetal anatomic ultrasound would still be needed during the second trimester. ${ }^{48}$

8. gNIPT also presents limitations in terms of scalability of gNIPT testing platforms. ${ }^{19}$

\section{Conclusion}

The diffusion of gNIPT into routine prenatal care is a major breakthrough in prenatal screening and diagnosis, notably because, based on initial studies, this technology has the potential to offer earlier results in the first trimester without multiple blood samples and substantially reduce the number of invasive procedures. ${ }^{49,50}$ However, its integration may be occurring too quickly.

The limitations of gNIPT may be underappreciated by providers and patients. ${ }^{51,52}$ 
At this time, the promising performance of gNIPT has been reported in high-risk pregnancies only for trisomy 21 and trisomy 18. This additional screening test may be an option for women classified as high-risk of aneuploidy who wish to avoid invasive diagnostic tests. Nevertheless, gNIPT should not currently be used as a first-tier prenatal screening test for DS, because its clinical validity and clinical utility have not yet been shown in pregnant women of average risk. Finally, for the moment, gNIPT is considered as a screening test and not as a diagnostic test. This means that a positive gNIPT result should always be confirmed by an invasive test, such as amniocentesis or chorionic villus sampling. In this context, it is crucial that providers carefully counsel patients about the test's advantages and limitations.

With regard to the clinical implementation of gNIPT in the future, three scenarios are possible: 1) NIPT might replace current screening approaches or be added to them (unique risk calculation, including screening tests from existing prenatal screening programs for DS and NIPT based on cffDNA); 2) gNIPT might be interposed between current screening and invasive prenatal diagnosis to filter out most of the screening false-positives (added to a subset of women as for contingent screening); or 3) gNIPT might replace invasive prenatal diagnosis if it is ever considered as a valid diagnostic test, as opposed to a screening test. Which of these options is followed will depend primarily on the technical accuracy of NIPT strategies (in terms of sensitivity and specificity) observed in validation studies of normal risk women and the available resources.

\section{Acknowledgments}

The authors are members of the research team of the Personalized Genomics for Prenatal Aneuploidy Screening Using Maternal Blood (PEGASUS) project, funded mainly by Genome Canada, the Canadian Institutes for Health Research, Genome Québec, Genome BC, Genome Alberta, the Ministère de l'Enseignement Supérieur, Recherche, Science et Technologie du Québec. FR holds a Ministère de la santé et des services sociaux/Fonds de recherche du Québec - Santé/Centre Hospitalier Universitaire de Québec research chair in Technology Assessment and Evidence-Based Laboratory Medicine.

\section{Disclosure}

The authors report no conflicts of interest in this work.

\section{References}

1. Greydanus DE, Pratt HD. Syndromes and disorders associated with mental retardation. Indian J Pediatr. 2005;72(10):859-864.
2. Chitayat D, Langlois S, Wilson RD; Genetics Committee of the Society of Obstetricians and Gynaecologists of Canada; Prenatal Diagnosis Committee of the Canadian College of Medical Geneticists. Prenatal screening for fetal aneuploidy in singleton pregnancies. $J$ Obstet Gynaecol Can. 2011;33(7):736-750.

3. Wright CF, Burton $H$. The use of cell-free fetal nucleic acids in maternal blood for non-invasive prenatal diagnosis. Hum Reprod Update. 2009;15(1):139-151.

4. Morain S, Greene MF, Mello MM. A new era in noninvasive prenatal testing. N Engl J Med. 2013;369(6):499-501.

5. Wright CF, Chitty LS. Cell-free fetal DNA and RNA in maternal blood: implications for safer antenatal testing. BMJ. 2009;339:b2451.

6. Lo YM, Corbetta N, Chamberlain PF, et al. Presence of fetal DNA in maternal plasma and serum. Lancet. 1997;350(9076):485-487.

7. Chiu RW, Chan KC, Gao Y, et al. Noninvasive prenatal diagnosis of fetal chromosomal aneuploidy by massively parallel genomic sequencing of DNA in maternal plasma. Proc Natl Acad Sci U S A. 2008:105(51):20458-20463.

8. Alberry M, Maddocks D, Jones M, et al. Free fetal DNA in maternal plasma in anembryonic pregnancies: confirmation that the origin is the trophoblast. Prenat Diagn. 2007;27(5):415-418.

9. Chan KC, Zhang J, Hui AB, et al. Size distributions of maternal and fetal DNA in maternal plasma. Clin Chem. 2004;50(1):88-92.

10. Lun FM, Chiu RW, Allen Chan KC, Yeung Leung T, Kin Lau T, Dennis Lo YM. Microfluidics digital PCR reveals a higher than expected fraction of fetal DNA in maternal plasma. Clin Chem. 2008;54(10): 1664-1672.

11. Illanes S, Denbow M, Kailasam C, Finning K, Soothill PW. Early detection of cell-free fetal DNA in maternal plasma. Early Hum Dev. 2007;83(9):563-566.

12. Lo YM, Zhang J, Leung TN, Lau TK, Chang AM, Hjelm NM. Rapid clearance of fetal DNA from maternal plasma. Am J Hum Genet. 1999;64(1):218-224.

13. Lo YM, Chiu RW. Genomic analysis of fetal nucleic acids in maternal blood. Annu Rev Genomics Hum Genet. 2012;13:285-306.

14. Baird PA, Anderson TW, Newcombe HB, Lowry RB. Genetic disorders in children and young adults: a population study. Am J Hum Genet. 1988;42(5):677-693.

15. Norbury G, Norbury CJ. Non-invasive prenatal diagnosis of single gene disorders: how close are we? Semin Fetal Neonatal Med. 2008;13(2): 76-83.

16. Lewis C, Hill M, Chitty LS. Non-invasive prenatal diagnosis for single gene disorders: experience of patients. Clin Genet. 2014;85(4): 336-342.

17. van der Schoot CE, Hahn S, Chitty LS. Non-invasive prenatal diagnosis and determination of fetal Rh status. Semin Fetal Neonatal Med. 2008;13(2):63-68.

18. Ashoor G, Syngelaki A, Wagner M, Birdir C, Nicolaides KH. Chromosome-selective sequencing of maternal plasma cell-free DNA for first-trimester detection of trisomy 21 and trisomy 18. Am J Obstet Gynecol. 2012;206(4):322. e321-e325.

19. Lench N, Barrett A, Fielding S, et al. The clinical implementation of non-invasive prenatal diagnosis for single-gene disorders: challenges and progress made. Prenat Diagn. 2013;33(6):555-562.

20. Chiu RW, Akolekar R, Zheng YW, et al. Non-invasive prenatal assessment of trisomy 21 by multiplexed maternal plasma DNA sequencing: large scale validity study. BMJ. 2011;342:c7401.

21. Dan S, Wang W, Ren J, et al. Clinical application of massively parallel sequencing-based prenatal noninvasive fetal trisomy test for trisomies 21 and 18 in 11,105 pregnancies with mixed risk factors. Prenat Diagn. 2012;32(13):1225-1232.

22. Li Y, Holzgreve W, Kiefer V, Hahn S. Maldi-tof mass spectrometry compared with real-time PCR for detection of fetal cell-free DNA in maternal plasma. Clin Chem. 2006;52(12):2311-2312.

23. Lo YM, Lun FM, Chan KC, et al. Digital PCR for the molecular detection of fetal chromosomal aneuploidy. Proc Natl Acad Sci U SA. 2007;104(32):13116-13121. 
24. Fan HC, Blumenfeld YJ, Chitkara U, Hudgins L, Quake SR. Noninvasive diagnosis of fetal aneuploidy by shotgun sequencing DNA from maternal blood. Proc Natl Acad Sci U S A. 2008;105(42): 16266-16271.

25. Poon LL, Leung TN, Lau TK, Chow KC, Lo YM. Differential DNA methylation between fetus and mother as a strategy for detecting fetal DNA in maternal plasma. Clin Chem. 2002;48(1):35-41.

26. Chiu RW, Sun H, Akolekar R, et al. Maternal plasma DNA analysis with massively parallel sequencing by ligation for noninvasive prenatal diagnosis of trisomy 21. Clin Chem. 2010;56(3):459-463.

27. Bianchi DW, Platt LD, Goldberg JD, Abuhamad AZ, Sehnert AJ, Rava RP; MatErnal BLood IS Source to Accurately diagnose fetal aneuploidy (MELISSA) Study Group. Genome-wide fetal aneuploidy detection by maternal plasma DNA sequencing. Obstet Gynecol. 2012;119(5):890-901.

28. Norton ME, Brar H, Weiss J, et al. Non-Invasive Chromosomal Evaluation (NICE) Study: results of a multicenter prospective cohort study for detection of fetal trisomy 21 and trisomy 18. Am J Obstet Gynecol. 2012;207(2):137.e1-137.e8.

29. Palomaki GE, Kloza EM, Lambert-Messerlian GM, et al. DNA sequencing of maternal plasma to detect Down syndrome: an international clinical validation study. Genet Med. 2011;13(11):913-920.

30. National Coalition for Health Professional Education in Genetics [homepage on the Internet]. Non-Invasive Prenatal Testing (NIPT) Factsheet; 2012 [updated August 15, 2012]. Available from: http://www. nchpeg.org/index.php?option=com_content\&view=article\&id=384\&I temid=255. Accessed October 3, 2013.

31. Benn P, Borell A, Chiu R, et al. Position statement from the Aneuploidy Screening Committee on behalf of the Board of the International Society for Prenatal Diagnosis. Prenat Diagn. 2013;33(7):622-629.

32. California Technology Assessment Forum [homepage on the Internet]. Fetal Aneuploidy Detection Via Maternal Plasma DNA Sequencing, part 2; 2012. [updated October 17, 2012]. Available from: http://www. ctaf.org/assessments/fetal-aneuploidy-detection-maternal-plasma-dnasequencing-part-2. Accessed October 3, 2013.

33. Langlois S, Brock JA, Wilson RD, et al; Genetics Committee. Current status in non-invasive prenatal detection of down syndrome, trisomy 18 , and trisomy 13 using cell-free DNA in maternal plasma. J Obstet Gynaecol Can. 2013;35(2):177-181.

34. American College of Obstetricians and Gynecologists Committee on Genetics. Committee Opinion No 545: Noninvasive prenatal testing for fetal aneuploidy. Obstet Gynecol. 2012;120(6): $1532-1534$.

35. Lutgendorf MA, Stoll KA, Knutzen DM, Foglia LM. Noninvasive prenatal testing: limitations and unanswered questions. Genet Med. 2014;16(4):281-285.

36. Nicolaides KH, Syngelaki A, Ashoor G, Birdir C, Touzet G. Noninvasive prenatal testing for fetal trisomies in a routinely screened first-trimester population. Am J Obstet Gynecol. 2012;207(5):374.e1-374.e6.
37. Fan HC, Quake SR. Sensitivity of noninvasive prenatal detection of fetal aneuploidy from maternal plasma using shotgun sequencing is limited only by counting statistics. PLoS One. 2010;5(5):e10439.

38. Chen EZ, Chiu RW, Sun H, et al. Noninvasive prenatal diagnosis of fetal trisomy 18 and trisomy 13 by maternal plasma DNA sequencing. PLoS One. 2011;6(7):e21791.

39. Sehnert AJ, Rhees B, Comstock D, et al. Optimal detection of fetal chromosomal abnormalities by massively parallel DNA sequencing of cell-free fetal DNA from maternal blood. Clin Chem. 2011;57(7): 1042-1049.

40. Wick JB, Johnson KJ, O’Brien J, Wick MJ. Second-trimester diagnosis of triploidy: a series of four cases. AJP Rep. 2013;3(1):37-40.

41. Chiu RW, Lo YM. Noninvasive prenatal diagnosis empowered by highthroughput sequencing. Prenat Diagn. 2012;32(4):401-406.

42. Lapaire O, Lu XY, Johnson KL, et al. Array-CGH analysis of cell-free fetal DNA in $10 \mathrm{~mL}$ of amniotic fluid supernatant. Prenat Diagn. 2007;27(7):616-621.

43. Simpson JL, Samango-Sprouse C. Prenatal diagnosis and 47,XXY. Am J Med Genet C Semin Med Genet. 2013;163C(1):64-70.

44. Wapner RJ, Martin CL, Levy B, et al. Chromosomal microarray versus karyotyping for prenatal diagnosis. N Engl J Med. 2012;367(23): 2175-2184.

45. Benn P, Borrell A, Crossley J, et al; International Society for Prenatal Diagnosis. Aneuploidy screening: a position statement from a committee on behalf of the Board of the International Society for Prenatal Diagnosis, January 2011. Prenat Diagn. 2011;31(6):519-522.

46. Canick JA, Kloza EM, Lambert-Messerlian GM, et al. DNA sequencing of maternal plasma to identify Down syndrome and other trisomies in multiple gestations. Prenat Diagn. 2012;32(8):730-734.

47. Lau TK, Jiang F, Chan MK, Zhang H, Lo PS, Wang W. Non-invasive prenatal screening of fetal Down syndrome by maternal plasma DNA sequencing in twin pregnancies. J Matern Fetal Neonatal Med. 2013;26(4):434-437.

48. van Lith JM, Benacerraf BR, Yagel S. Current controversies in prenatal diagnosis 2: Down syndrome screening: is ultrasound better than cell-free nucleic acids in maternal blood? Prenat Diagn. 2011;31(3): 231-234.

49. Sehnert AJ, Rava RP, Bianchi DW. A new era in noninvasive prenatal testing. N Engl J Med. 2013;369(22):2164-2165.

50. Ashwood ER, Palomaki GE. A new era in noninvasive prenatal testing. N Engl J Med. 2013;369(22):2164.

51. Norton ME, Rose NC, Benn P. Noninvasive prenatal testing for fetal aneuploidy: clinical assessment and a plea for restraint. Obstet Gynecol. 2013;121(4):847-850

52. Weaver C. Tough Calls on Prenatal Tests. The Wall Street Journal. April 3, 2013
The Application of Clinical Genetics

\section{Publish your work in this journal}

The Application of Clinical Genetics is an international, peer-reviewed open access journal that welcomes laboratory and clinical findings in the field of human genetics. Specific topics include: Population genetics; Functional genetics; Natural history of genetic disease; Management of genetic disease; Mechanisms of genetic disease; Counseling and ethical

\section{Dovepress}

issues; Animal models; Pharmacogenetics; Prenatal diagnosis; Dysmorphology. The manuscript management system is completely online and includes a very quick and fair peer-review system, which is all easy to use. Visit http://www.dovepress.com/testimonials.php to read real quotes from published authors. 